\title{
Optimization of Thermal Friction Drilling Process Based on Taguchi Method and Fuzzy Logic Technique
}

\author{
Sara A. El-Bahloul \\ Mansoura University \\ Faculty of Engineering \\ Mansoura, Egypt
}

\author{
Hazem E. El-Shourbagy \\ Mansoura University \\ Faculty of Engineering \\ Mansoura, Egypt
}

\author{
Tawfik T. El-Midany \\ Mansoura University \\ Faculty of Engineering \\ Mansoura, Egypt
}

\begin{abstract}
The main purpose of this research is to study the optimal process parameters for thermal friction drilling process on AISI 304 stainless steel. The experiments were conducted based on Taguchi experimental design method, and the multiple performance characteristics correlated with the resultant axial force, radial force, hole diameter dimensional error, roundness error, and bushing length, were investigated by fuzzy logic technique. The significant process parameters that most intensively affected the multiple performance characteristics and the optimal combination levels of process parameters were determined through the analysis of variance and the response graph. A test rig was manufactured at Shoman Company - Egypt to perform the experimental work, and the tools were offered by Flowdrill Company - Germany. Experimental results confirm that this approach is simple, effective and efficient for simultaneous optimization of multiple quality characteristics in thermal friction drilling process, as the bushing length produced is more than five times the workpiece thickness.
\end{abstract}

Keywords: Thermal friction drilling; Optimization; Process parameters; Taguchi; Fuzzy logic; Bushing length

\section{INTRODUCTION}

Taguchi method is one of the simplest and effective solution for parameter design and experimental planning $[1,2]$. It analyzes the influence of parameter variation to performance characteristics. Thereby, an optimal result can be obtained so that the sensitivity of performance characteristics in respect to parameter variation. Several research works have successfully applied this method to investigate the performance characteristics of processes. However, Taguchi method has shown some drawbacks in dealing with the problems of multiple performance characteristics $[3,4]$.

The theory of fuzzy logics, initiated by Zadeh in 1965 [5], has proven to be useful for dealing with uncertain and vague information. Since the definition of performance characteristics used for this research such as lower-the-better, higher-the-better, and nominal-the-better contains a certain degree of uncertainty and vagueness. Therefore, in the present work fuzzy logics can be a proper basis to perform the optimization procedure with complicated multiple performance characteristics.

Thermal friction drilling is a nontraditional drilling method that utilizes the heat generated from the friction interface between a rotating conical tool and the workpiece, and the heat will soften the workpiece and facilitate the tool to penetrate into the workpiece plate. Since it is no-chip process, the surface of the drilled hole would not be damaged by the burr extrusion during the drilling process. Therefore, tool service life could be increased, and the processing elapsed time and drilling cost would be intensively reduced. Another important feature of thermal friction drilling is that it could form a bushing that can provide a longer contact area, which can bear a shaft firmly as well as taped to create an internal screw without welding a nut. This is a unique feature which cannot be achieved by common drilling processes [6].

Following recent technological developments, stainless steel materials with anti-oxidizing, anticorrosive, and shiny surface features and outstanding characteristics like high toughness, high work-hardening coefficient, and low temperature conductivity have been applied in electronic, biochemical, and medical instrumentation equipment. Although these outstanding features reveal the distinguished advantages to extend its applications in modern industries, stainless steel is hard to process and results in a serious tool wear and a rough surface of a part in machining process. The novel thermal friction drilling process needs a further and comprehensive study to understand the effects of drilling performance on stainless steels [7].

Referred to thermal friction drilling, there are recently few related research works. In this respect, Miller et al. [8] applied friction drilling to characterize the microstructures and indentation hardness changes in the friction drilling of carbon steel, alloy steel, aluminum, and titanium. Miller et al. [9] suggested that preheating the brittle material (cast metal) workpiece and using high speed drilling condition could generate a cylindrical shaped bushing without significant radial fracture. Lee et al. [10] had successfully applied friction drilling for machining cast superalloy IN-713LC to assess the roundness, the surface roughness, and the hardness of machined-hole-wall. Lee et al. [11] utilized tungsten carbide drills to investigate the benefits of coating on machining AISI 304 stainless steel, and the experimental results showed that the coated drills revealed less tool wear than uncoated ones. Chow et al. [12] conducted the experiments to explore the optimal tool friction angle and friction contact area ratio on AISI304 stainless steel correlated with surface roughness and bushing length. From those works, the optimal machining parameters combination for friction drilling process neither explored nor discussed the important issues such as the geometric shape of the drills and cutting parameters that will have effects on the resultant axial force, radial force, hole diameter dimensional error, roundness error, or bushing length.

The main purpose of this paper is to present the optimization of the thermal friction drilling process parameters; namely, tool cylindrical region diameter $(\mathrm{d})$, friction angle $(\beta)$, friction contact area ratio (FCAR), workpiece thickness (t), feed rate (FR), and rotational speed (RS), on austenite stainless steel (AISI 304). Thus, the axial force (AF), radial force (RF), hole diameter dimensional error (DE), roundness error (RE), and bushing length (BL) together were measured, and the optimal combination levels of process parameters were also explored and proved by a confirmation test. Thus, the performance of thermal friction 
drilling process on difficult-to-machine materials such as stainless steel would be ascertained to fit requirements of modern industrial applications.

\section{EXPERIMENTAL APPARATUS AND DESIGN}

Figure 1 shows the test rig that is designed to carry out the experimental work. The test rig is manufactured at Shoman Company - Egypt. It has two induction motors, one for performing high rotational speed up to $4500 \mathrm{rpm}$, and the other to get feed rate up to $200 \mathrm{~mm} / \mathrm{min}$. The tool is held by standard collets. Total of 18 thermal friction tools are used to perform all experiments. The tools are offered by Flowdrill Company Germany. They are made of uncoated tungsten carbide.

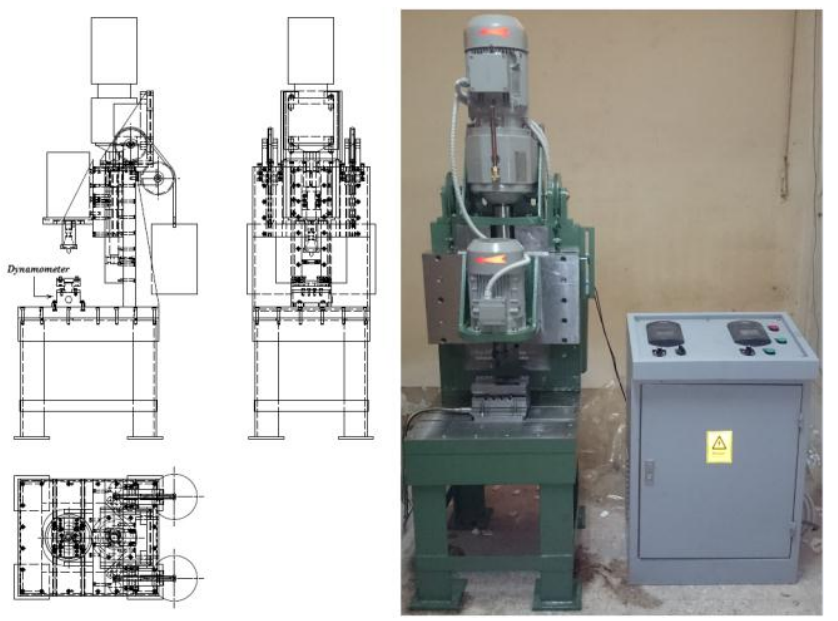

Figure. 1 The test rig

Three values for each of the six parameters are selected, as shown in Table 1. In this respect, no research work had combined six parameters together. In this study, an orthogonal array L18 [13] is applied to design the experiments. Each process parameter is assigned to a column and 18 process parameter combinations are required, as shown in Table 2.

Table 1. Process parameters and their levels

\begin{tabular}{|c|c|c|c|c|}
\hline $\begin{array}{c}\text { Process } \\
\text { Parameter }\end{array}$ & Unit & Level 1 & Level 2 & Level 3 \\
\hline $\mathrm{d}$ & $\mathrm{mm}$ & 5.4 & 7.3 & 9.2 \\
\hline$\beta$ & degree & $30^{\circ}$ & $45^{\circ}$ & $60^{\circ}$ \\
\hline FCAR & - & $50 \%$ & $75 \%$ & $100 \%$ \\
\hline $\mathrm{t}$ & $\mathrm{mm}$ & 1 & 2 & 3 \\
\hline $\mathrm{RS}$ & $\mathrm{rpm}$ & 1500 & 2500 & 3500 \\
\hline $\mathrm{FR}$ & $\mathrm{mm} / \mathrm{min}$ & 60 & 100 & 140 \\
\hline
\end{tabular}

The AF and RF were measured by a multi-component dynamometer (type 9257B). The DE and RE were measured by a coordination measuring machine (Status CMM). The BL was measured by a micro Vernier.

\section{ANALYSIS AND DISCUSSION}

Figure 2 illustrates the optimal process parameters determination steps according to Taguchi method and fuzzy logic technique.

\subsection{Taguchi Method}

To obtain the optimal machining performance, the minimum values of $\mathrm{AF}, \mathrm{RF}, \mathrm{DE}$, and RE is desired. Hence, the smaller-thebetter signal-to-noise $(\mathrm{S} / \mathrm{N})$ ratio is adopted, which is expressed in
Equation 1. Also, to get the maximum BL, the larger-the-better $\mathrm{S} / \mathrm{N}$ ratio is used and can be expressed in Equation 2 [1].

Table 2. Experimental layout of L18 orthogonal array

\begin{tabular}{|c|c|c|c|c|c|c|}
\hline $\begin{array}{c}\text { Exp. } \\
\text { No. }\end{array}$ & $\begin{array}{c}\mathbf{d} \\
(\mathbf{m m})\end{array}$ & $\begin{array}{c}\boldsymbol{\beta} \\
(\mathbf{d e g r e e})\end{array}$ & $\begin{array}{c}\text { FCAR } \\
(\boldsymbol{\%})\end{array}$ & $\begin{array}{c}\mathbf{t} \\
(\mathbf{m m})\end{array}$ & $\begin{array}{c}\mathbf{F R} \\
(\mathbf{m m} / \mathbf{m i n})\end{array}$ & $\begin{array}{c}\mathbf{R S} \\
(\mathbf{r p m})\end{array}$ \\
\hline 1 & 5.4 & 30 & 50 & 1 & 60 & 2500 \\
\hline 2 & 5.4 & 30 & 75 & 3 & 140 & 1500 \\
\hline 3 & 5.4 & 45 & 50 & 2 & 100 & 1500 \\
\hline 4 & 5.4 & 45 & 100 & 1 & 140 & 3500 \\
\hline 5 & 5.4 & 60 & 75 & 2 & 60 & 3500 \\
\hline 6 & 5.4 & 60 & 100 & 3 & 100 & 2500 \\
\hline 7 & 7.3 & 30 & 100 & 1 & 100 & 1500 \\
\hline 8 & 7.3 & 30 & 100 & 2 & 60 & 3500 \\
\hline 9 & 7.3 & 45 & 50 & 3 & 140 & 3500 \\
\hline 10 & 7.3 & 45 & 75 & 2 & 100 & 2500 \\
\hline 11 & 7.3 & 60 & 50 & 3 & 60 & 1500 \\
\hline 12 & 7.3 & 60 & 75 & 1 & 140 & 2500 \\
\hline 13 & 9.2 & 30 & 50 & 2 & 140 & 2500 \\
\hline 14 & 9.2 & 30 & 75 & 3 & 100 & 3500 \\
\hline 15 & 9.2 & 45 & 75 & 1 & 60 & 1500 \\
\hline 16 & 9.2 & 45 & 100 & 3 & 60 & 2500 \\
\hline 17 & 9.2 & 60 & 50 & 1 & 100 & 3500 \\
\hline 18 & 9.2 & 60 & 100 & 2 & 140 & 1500 \\
\hline
\end{tabular}

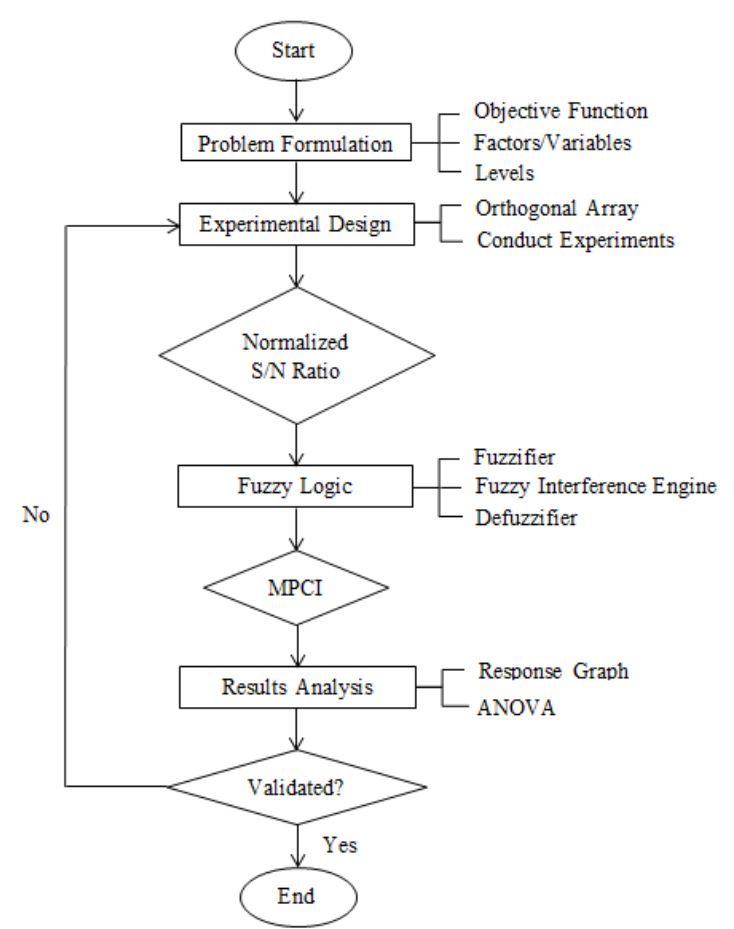

Figure 2. The optimal process parameters determination steps flow chart

$$
\begin{aligned}
& S / N=-10 \log \frac{\sum_{i=1}^{n} y_{i}^{2}}{n} \\
& S / N=-10 \log \frac{\sum_{i=1}^{n} y_{i}^{-2}}{n}
\end{aligned}
$$

where yi is the measured quality value, and $\mathrm{n}$ is the number of trails for each experiment ( $n=3$ trails). Since the $\mathrm{S} / \mathrm{N}$ ratios for the $\mathrm{AF}, \mathrm{RF}, \mathrm{DE}, \mathrm{RE}$, or $\mathrm{BL}$ are in different ranges, the $\mathrm{S} / \mathrm{N}$ ratios are normalized to the range of $0-1$. The normalized equation is expressed as [3]: 


$$
N \eta_{p}=\frac{(S / N)_{P}-(S / N)_{\min }}{(S / N)_{\max }-(S / N)_{\min }}
$$

where $\mathrm{N} \eta \mathrm{p}$ is the normalized $\mathrm{S} / \mathrm{N}$ ratio, $(\mathrm{S} / \mathrm{N}) \mathrm{p}$ is the value of $\mathrm{S} / \mathrm{N}$ for each experiment number $\mathrm{p},(\mathrm{S} / \mathrm{N}) \max$ and $(\mathrm{S} / \mathrm{N}) \min$ are the maximum and minimum values of $\mathrm{S} / \mathrm{N}$ for all experiments. Table 3 shows the resultant $\mathrm{S} / \mathrm{N}$ and $\mathrm{N} \eta \mathrm{p}$ for the $\mathrm{AF}, \mathrm{RF}$, and $\mathrm{DE}$. Noteworthy, the experiments 2, 11, and 18 didn't complete as shown in Figure 3, because these experiments performed under the lowest rotational speed with higher workpiece thickness, so the heat produced due to friction is insufficient to completely perform the experiment.

Table 3. S/N ratios and Nip

\begin{tabular}{|c|c|c|c|c|c|c|c|c|c|c|}
\hline \multirow{2}{*}{$\begin{array}{c}\text { Exp. } \\
\text { No. }\end{array}$} & \multicolumn{2}{|c|}{$\mathbf{A F}$} & \multicolumn{2}{c|}{$\mathbf{R F}$} & \multicolumn{2}{c|}{$\mathbf{D E}$} & \multicolumn{2}{c|}{$\mathbf{R E}$} & \multicolumn{2}{c|}{$\mathbf{B L}$} \\
\hline & $\mathbf{S} / \mathbf{N}$ & $\mathbf{N} \boldsymbol{\eta}_{\mathbf{p}}$ & $\mathbf{S} / \mathbf{N}$ & $\mathbf{N} \boldsymbol{\eta}_{\mathbf{p}}$ & $\mathbf{S} / \mathbf{N}$ & $\mathbf{N} \boldsymbol{\eta}_{\mathbf{p}}$ & $\mathbf{S} / \mathbf{N}$ & $\mathbf{N} \boldsymbol{\eta}_{\mathbf{p}}$ & $\mathbf{S} / \mathbf{N}$ & $\mathbf{N} \boldsymbol{\eta}_{\mathbf{p}}$ \\
\hline 1 & -50.07 & 1.00 & -37.44 & 1.00 & 37.84 & 1.00 & 34.92 & 0.43 & 14.12 & 0.22 \\
\hline 2 & - & - & - & - & - & - & - & - & - & - \\
\hline 3 & -59.72 & 0.37 & -43.74 & 0.47 & 24.35 & 0.39 & 33.32 & 0.37 & 16.08 & 0.47 \\
\hline 4 & -51.68 & 0.89 & -40.64 & 0.73 & 29.08 & 0.60 & 50.06 & 1.00 & 12.45 & 0.00 \\
\hline 5 & -56.66 & 0.57 & -43.85 & 0.46 & 22.09 & 0.28 & 30.06 & 0.24 & 16.17 & 0.48 \\
\hline 6 & -64.65 & 0.05 & -48.91 & 0.03 & 19.99 & 0.19 & 34.30 & 0.40 & 17.10 & 0.6 \\
\hline 7 & -51.13 & 0.93 & -39.93 & 0.79 & 26.58 & 0.49 & 38.76 & 0.57 & 14.13 & 0.22 \\
\hline 8 & -55.62 & 0.64 & -41.12 & 0.69 & 20.13 & 0.19 & 24.92 & 0.05 & 17.25 & 0.62 \\
\hline 9 & -61.69 & 0.24 & -44.74 & 0.38 & 23.42 & 0.34 & 29.88 & 0.24 & 18.79 & 0.81 \\
\hline 10 & -58.09 & 0.48 & -42.74 & 0.55 & 27.81 & 0.54 & 29.14 & 0.21 & 17.16 & 0.60 \\
\hline 11 & - & - & - & - & - & - & - & - & - & - \\
\hline 12 & -51.94 & 0.88 & -40.62 & 0.73 & 25.53 & 0.44 & 43.8 & 0.76 & 13.69 & 0.16 \\
\hline 13 & -57.62 & 0.51 & -45.42 & 0.33 & 23.38 & 0.34 & 25.55 & 0.07 & 18.57 & 0.78 \\
\hline 14 & -59.43 & 0.39 & -49.27 & 0.00 & 15.88 & 0.00 & 23.66 & 0.00 & 20.25 & 1.00 \\
\hline 15 & -51.44 & 0.91 & -40.57 & 0.73 & 21.18 & 0.24 & 32.08 & 0.32 & 15.00 & 0.33 \\
\hline 16 & -65.36 & 0.00 & -46.6 & 0.23 & 16.59 & 0.03 & 25.95 & 0.09 & 20.15 & 0.99 \\
\hline 17 & -50.22 & 0.99 & -42.67 & 0.56 & 23.98 & 0.37 & 30.51 & 0.26 & 15.95 & 0.45 \\
\hline 18 & - & - & - & - & - & - & - & - & - & - \\
\hline
\end{tabular}

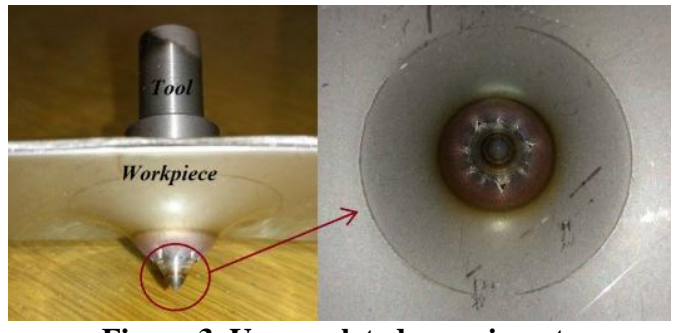

Figure 3. Uncompleted experiments

\subsection{Fuzzy Logic Technique}

The fuzzy inference system has four parts, the fuzzifier, fuzzy rule base, fuzzy inference engine, and defuzzifier as shown in Figure 4. The fuzzifier transforms crisp input into suitable semantic fuzzy information. The fuzzy rule base stores the rules and knowledge required for solving related problems, and describes the relationship between system input and output. The fuzzy inference engine is the core of the fuzzy system, and simulates thinking and decision-making models of humans via approximate reasoning or fuzzy inference, and finds solutions to existing problems. The defuzzifier transforms fuzzy information inferred by the fuzzy inference engine into crisp output. The defuzzifier uses the center of gravity to transform fuzzy information into crisp output.

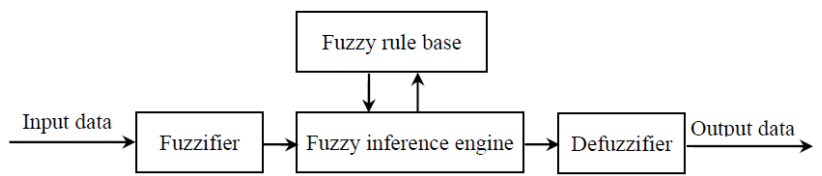

Figure 4. Schematic of the fuzzy prediction system
This study used MATLAB software to construct the inference model of the multiple performance characteristic index (MPCI), where $\mathrm{N} \eta p$ of the $\mathrm{AF}, \mathrm{RF}, \mathrm{DE}, \mathrm{RE}$, and $\mathrm{BL}$ are taken as the input

variables for the fuzzy logic system, and the MPCI is the output variable. Table 4 shows the MPCI results and the total mean of the MPCI $(\eta \mathrm{m})$ for all the 18 experiments.

Table 4. Result for the MPCI

\begin{tabular}{|c|c|}
\hline Exp. No. & MPCI \\
\hline 1 & 0.76100 \\
\hline 2 & - \\
\hline 3 & 0.48600 \\
\hline 4 & 0.63400 \\
\hline 5 & 0.49900 \\
\hline 6 & 0.24400 \\
\hline 7 & 0.66400 \\
\hline 8 & 0.43000 \\
\hline 9 & 0.46900 \\
\hline 10 & 0.50000 \\
\hline 11 & - \\
\hline 12 & 0.61800 \\
\hline 13 & 0.50000 \\
\hline 14 & 0.35000 \\
\hline 15 & 0.60300 \\
\hline 16 & 0.32900 \\
\hline 17 & 0.62500 \\
\hline 18 & - \\
\hline $\boldsymbol{\eta}_{\boldsymbol{m}}$ & 0.42844 \\
\hline
\end{tabular}

Since the experimental design is orthogonal, it is then possible to separate out the effect of each process parameter at different levels. For example, the mean of MPCI for the cylindrical region 
diameter parameter at levels 1,2 and 3 can be calculated by averaging the MPCI for experiments 1-6, 7-12, and 13-18, respectively (Table 2), so the mean of MPCI for each level of the other process parameters can be computed in a similar manner. Then the results are summarized in a table called the response table (Table 5). Figure 5 shows the response graph for the MPCI mean. Basically, the larger the MPCI mean, the better the performance characteristic. However, the relative importance amongst the process parameters for the performance characteristic still needs to be known so that the optimal combinations of the process parameter levels can be determined more accurately.

Table 5. MPCI mean response table

\begin{tabular}{|c|c|c|c|c|c|}
\hline \multirow{2}{*}{$\begin{array}{c}\text { Process } \\
\text { Parameter }\end{array}$} & \multicolumn{3}{|c|}{ MPCI Mean } & Max- & Rank \\
\cline { 2 - 4 } & Level 1 & Level 2 & Level 3 & Min & \\
\hline $\mathrm{d}$ & 0.4373 & 0.4468 & 0.4012 & 0.0457 & 6 \\
\hline$\beta$ & 0.4508 & 0.5035 & 0.331 & 0.1725 & 3 \\
\hline FCAR & 0.4735 & 0.4283 & 0.3835 & 0.09 & 5 \\
\hline t & 0.6508 & 0.4025 & 0.232 & 0.4188 & 1 \\
\hline FR & 0.437 & 0.4782 & 0.3702 & 0.108 & 4 \\
\hline RS & 0.2922 & 0.492 & 0.5012 & 0.209 & 2 \\
\hline
\end{tabular}

\subsection{Analysis of Variance}

The statistical analysis of variance (ANOVA) is to investigate which process parameters significantly affect the performance characteristics. This is accomplished by separating the total variability of the multi performance characteristics indexes, which is measured by the sum of the squared deviations from the total mean of the MPCI, into contributions by each of the process parameter and the error. The total sum of the squared deviations (SST) can be calculated as [13]:

$$
S S_{T}=\sum_{j=1}^{p}\left(\mathrm{MPCI}_{j}-\mathrm{n}_{m}\right)^{2}
$$

where $\mathrm{p}$ is the number of experiments in the orthogonal array. SST is decomposed into two sources: the sum of the squared deviations due to each process parameter and the sum of the squared error. The percentage contribution by each of the process parameter in the total sum of the squared deviations can be used to evaluate the importance of the process parameter change on the performance characteristics. The results of ANOVA (Table 6) indicate that $\mathrm{t}$ and $\mathrm{RS}$ are the most significant process parameters in affecting the $\mathrm{AF}, \mathrm{RF}, \mathrm{DE}, \mathrm{RE}$, and $\mathrm{BL}$ together.

Based on the above discussion, the optimal process parameters combination is: $\mathrm{d}=7.3 \mathrm{~mm}, \beta=45^{\circ}, \mathrm{FCAR}=50 \%, \mathrm{t}=1 \mathrm{~mm}$, feed rate $\mathrm{FR}=100 \mathrm{~mm} / \mathrm{min}$, and rotational speed $\mathrm{RS}=3500 \mathrm{rpm}$, for the proposed experimental levels.
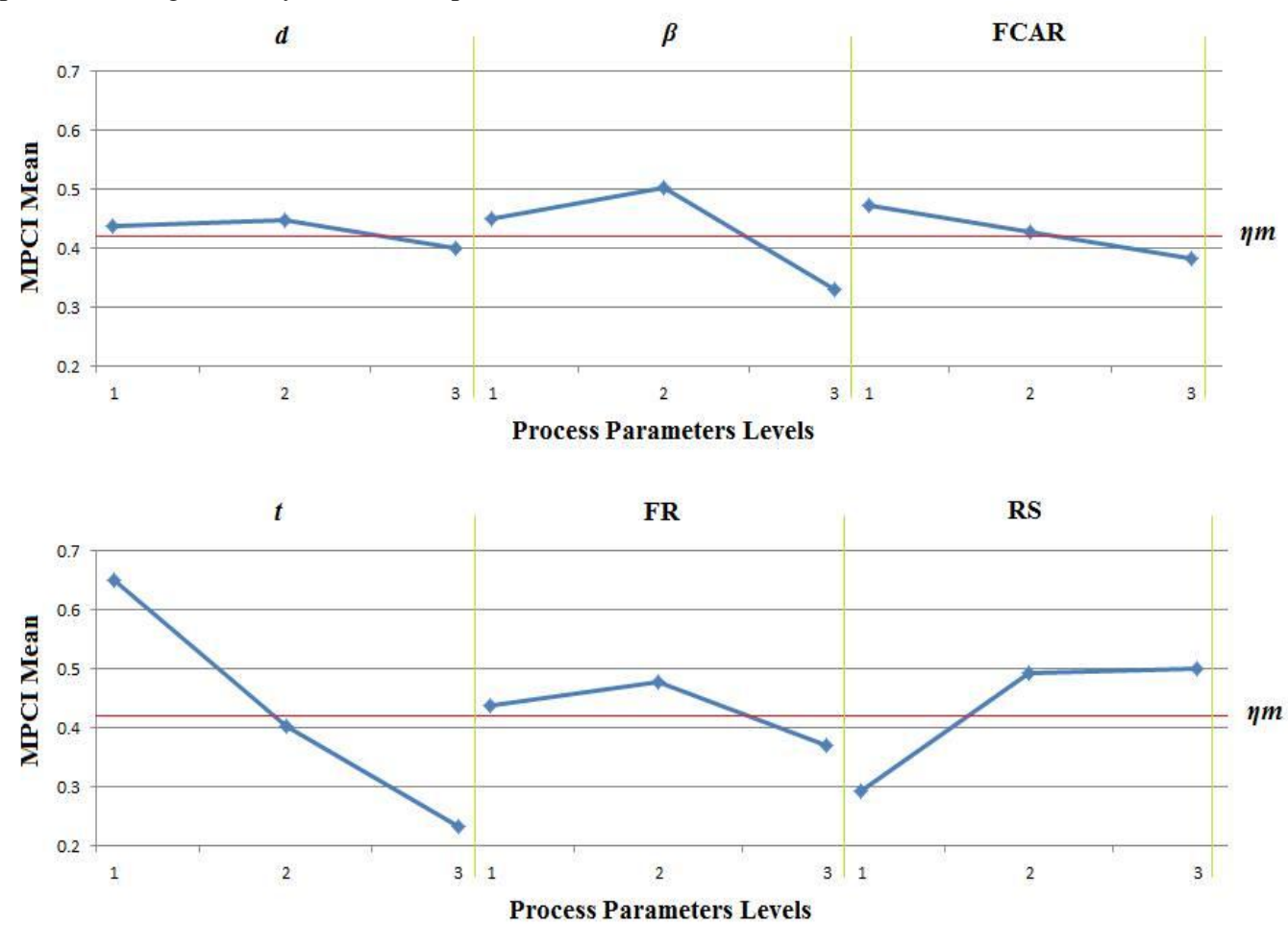

Figure 5. MPCI mean response graph

Table 6. Result of ANOVA

\begin{tabular}{|c|c|c|}
\hline $\begin{array}{c}\text { Process } \\
\text { Parameters }\end{array}$ & $\begin{array}{c}\text { Sum of } \\
\text { Square }\end{array}$ & $\begin{array}{c}\text { Contribution } \\
(\boldsymbol{\%})\end{array}$ \\
\hline $\mathrm{d}$ & 0.00697 & 0.7460 \\
\hline$\beta$ & 0.09378 & 10.037 \\
\hline FCAR & 0.0243 & 2.6009 \\
\hline $\mathrm{t}$ & 0.53232 & 56.975 \\
\hline FR & 0.03565 & 3.8157 \\
\hline RS & 0.1674 & 17.917 \\
\hline
\end{tabular}

www.ijsea.com

\begin{tabular}{|c|c|c|}
\hline Error & 0.07389 & 7.9086 \\
\hline Total & 0.9343 & 100 \\
\hline
\end{tabular}

\subsection{Confirmation Test}

Once the optimal level of the process parameters has been selected, the final step is to predict and verify the improvement of the performance characteristic using the optimal level of the process parameters. The predicted $\mathrm{S} / \mathrm{N}$ ratio $\eta$ using the optimal level of the process parameters can be calculated as: 
International Journal of Science and Engineering Applications

Volume 4 Issue 2, 2015, ISSN-2319-7560 (Online)

$$
\eta=\eta_{m}+\sum_{j=1}^{q}\left(\eta_{j}-\eta_{m}\right)
$$

where $\eta j$ is the mean of the MPCI at the optimal level, and $q$ is the number of the process parameters that significantly affect the multiple performance characteristics. Table 7 displays the results of the confirmation experiment. This table indicates that the experimental observed values obtained from the optimal combination levels of process parameters were improved compared to the minimum trails mean results for each experiment of the performed 18 experiments at $\mathrm{t}=1 \mathrm{~mm}$. Experiment number 17 achieved BL more than that of the optimal experiment, as it performed at $d=9.2 \mathrm{~mm}$, so more material is pushed leading to more BL, but still the BL produced in the optimal experiment more than five times the workpiece thickness. Also the DE produced in experiment number 1 is less than that of the optimal experiment, as it performed at smaller tool diameter $\mathrm{d}=5.4 \mathrm{~mm}$ so less error is produced, but still the increase in the DE at the optimal experiment is very small.

Table 7. Results of the confirmation experiment Best Suitable Process Parameter Confirmation

\begin{tabular}{|c|c|c|}
\hline \multirow{4}{*}{$\begin{array}{c}\text { Setting levels } \\
\text { MPCI }\end{array}$} & \multicolumn{2}{|c|}{ Best Suitable Process Parameter Confirmation } \\
\hline & Predicted & Experimental \\
\hline & \multicolumn{2}{|c|}{$\mathrm{d} 2-\beta 2-\mathrm{FCAR} 1-\mathrm{t} 1-\mathrm{FR} 2-\mathrm{RS} 3$} \\
\hline & 0.72356 & 0.783 \\
\hline & \multicolumn{2}{|c|}{ Performed Experiments Results } \\
\hline & $\begin{array}{c}\text { Minimum of } 1 \mathrm{~mm} \\
\text { experiments }\end{array}$ & Optimal experiment \\
\hline $\mathbf{A F}$ & $318.667 \mathrm{~N}$ & $292 \mathrm{~N}$ \\
\hline RF & $74 \mathrm{~N}$ & $50 \mathrm{~N}$ \\
\hline DE & $0.0092 \mathrm{~mm}$ & $0.013 \mathrm{~mm}$ \\
\hline RE & $0.0031 \mathrm{~mm}$ & $0.002 \mathrm{~mm}$ \\
\hline BL & $6.2733 \mathrm{~mm}$ & $5.78 \mathrm{~mm}$ \\
\hline
\end{tabular}

\section{CONCLUSIONS}

This paper has presented the use of Taguchi method and fuzzy logic technique for the optimization of the thermal friction drilling process of AISI 304 stainless steel. Experimental data and statistical results have supported the following conclusions:

- The workpiece thickness and the rotational speed are the most significant process parameters, which obviously affected the AF, RF, DE, RE, and BL together in thermal friction drilling for the proposed experimental levels.

- The optimal process parameters combination is: $\mathrm{d}=7.3 \mathrm{~mm}$, $\beta=45^{\circ}, \mathrm{FCAR}=50 \%, \mathrm{t}=1 \mathrm{~mm}, \mathrm{FR}=100 \mathrm{~mm} / \mathrm{min}$, and $\mathrm{RS}$ $=3500 \mathrm{rpm}$, for the proposed experimental levels.

- The performance characteristics such as AF, RF, DE, RE, and $\mathrm{BL}$ are improved through this approach. The $\mathrm{BL}$ produced is more than five times the workpiece thickness.

- This study can be applied on the friction drilling of various malleable metals including mild steel, stainless steel, copper, brass, and aluminum to generate precision holes. Also different machining conditions can be considered, so as to build a Computer Aided Process Planning expert system of thermal friction drilling process with the goal of automation.

\section{ACKNOWLEDGEMENTS}

The first author would like to acknowledge Flowdrill Company in Germany for offering the needed tools. Also she would like to acknowledge Shoman Company in Egypt for their great help and support in offering the facilities and tools needed to conduct this work.

\section{REFERENCES}

[1] Ross, P. 1988 Taguchi techniques for quality engineering: loss function, orthogonal experiments, parameter and tolerance design. second edition, McGraw-Hill book CoSingapore Copyright (C) 1996, ISBN 0-07-114663-6.

[2] Taguchi, G., Chowdhury, S., and Wu, Y. 2005 Taguchi quality engineering handbook. ISBN 0-471-41334-8, John Wiely \& Sons, Inc.

[3] Hsiang, S., and Lin Y. 2009 Optimization of the extrusion process for Magnesium alloy sheets using the fuzzy based Taguchi method. the Arabian journal for science and engineering, volume 34, number 1c.

[4] Puri, Y., and Deshpande, N. 2004 Simultaneous optimization of multiple quality characteristics of WEDM based on fuzzy logic and Taguchi technique. Proceedings of the Fifth Asia Pacific Industrial Engineering and Management Systems Conference.

[5] Yen, J., and Langari, R. 1999 Fuzzy Logic: intelligence, control, and information. Prentice hall, upper saddle river, New Jersey 07458, ISBN: 0-13-525817-0.

[6] Wu, C., Fang, T., and Kuo, C. 2014 Atomistic simulation of nanodrilling mechanics and mechanism on $\mathrm{Cu}$ substrates. Appl. Phys. A, Materials science and processing, DOI 10.1007/s00339-014-8732-5.

[7] Ku, W., Hung, C., Lee, S., and Chow, H. 2010 Optimization in thermal friction drilling for SUS 304 stainless steel. Springer-Verlag London Limited 2010, Int. J. Adv. Manuf. Technol. 53:935-944, DOI 10.1007/s00170-010-2899-5.

[8] Miller, S., Tao, J., and Shih, A. 2005 Microstructural alterations associated with friction drilling of steel, aluminum, and titanium. JMEPEG 14:647-653 CASM International, DOI: 10.1361/105994905X645581 0599495.

[9] Miller, S., Tao, J., and Shih, A. 2005 Friction drilling of cast metals. International Journal of Machine Tools \& Manufacture 46 1526-1535, DOI 10.1016/j.ijmachtools. 2005.09.003.

[10] Lee, S., Chow, H., and Yan, B. 2007 Friction drilling of IN713LC cast superalloy. Materials and Manufacturing Processes, 22: 893-897, 2007, Copyright (C) Taylor \& Francis Group, LLC, ISSN: $1042-6914$ print/1532-2475 online, DOI: 10.1080/10426910701451697.

[11] Lee, S., Chow, H., Huang, F., and Yan, B. 2008 Friction drilling of austenitic stainless steel by uncoated and PVD $\mathrm{AlCrN}-$ and TiAlN-coated tungsten carbide tools. International Journal of Machine Tools \& Manufacture 49, 0890-6955/\$, Crown Copyright (C) Published by Elsevier Ltd., DOI: 10.1016/j.ijmachtools.2008.07.012.

[12] Ku, W., Chow, H., Lin, Y., Wang, D., and Yang, L. 2010 Optimization of thermal friction drilling using grey relational analysis. eAdvanced Materials Research Vols. 154-155 pp 1726-1738, Copyright (C) Trans. Tech. Publications, Switzerland DOI: 10.4028/www.scientific.net/AMR.154155. 1726 .

[13] Tsai, P., Gilmour, S., and Mead, R. 2000 Projective threelevel main-effects designs robust to model uncertainty. Biometrika, 87, 2 pp. 467-475 (C) Biometrika Trust printed in Great Britain. 